\title{
Space Molecular Sink Simulator \\ Facility Design
}

James B. Stephens
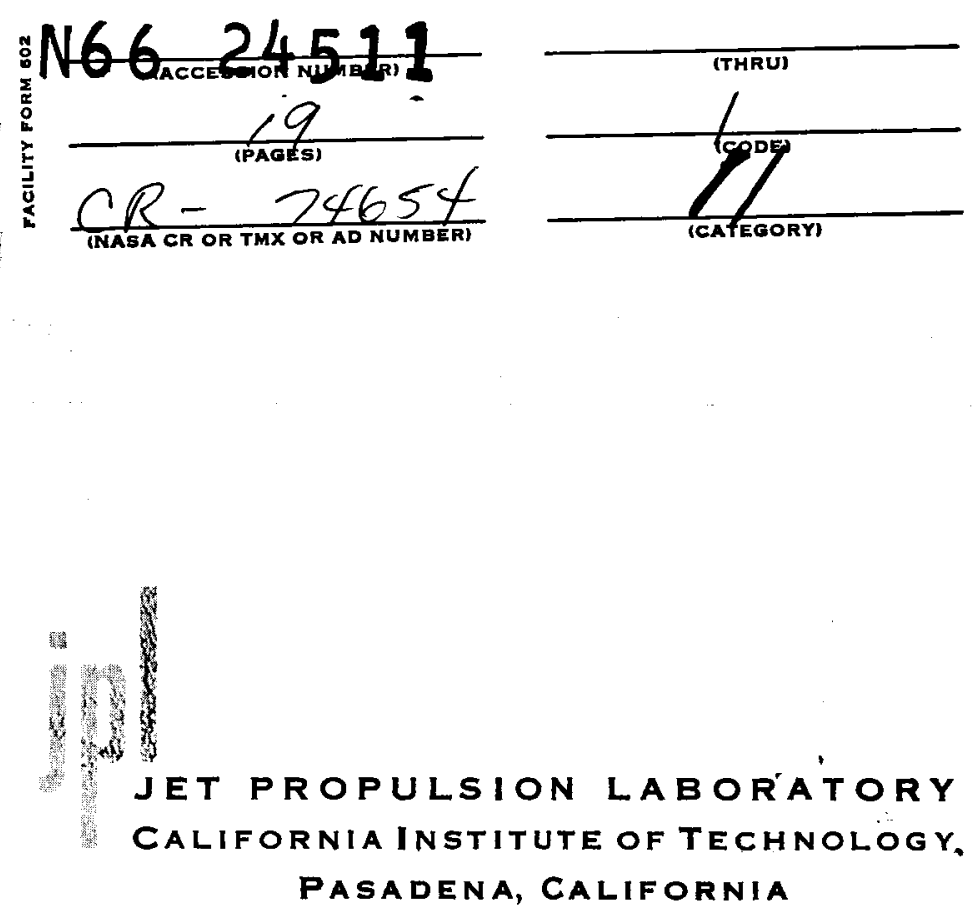

March 15, 1966 
NATIONAL AERONAUTICS AND SPACE ADMINISTRATION

Technical Report No. 32-901

\section{Space Molecular Sink Simulator \\ Facility Design}

James B. Stephens

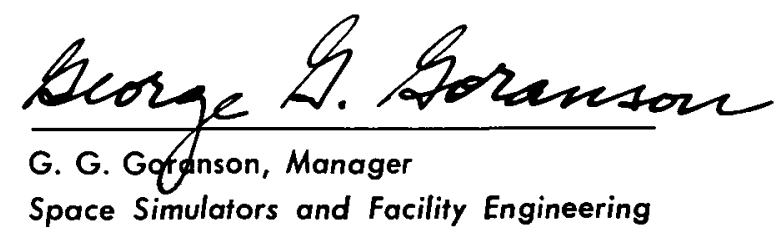

JET PROPULSION LABORATORY

CALIFORNIA INSTITUTE OF TECHNOLOGY

PASADENA, CALIFORNIA

March 15, 1966 
Copyright (c) 1966

Jet Propulsion Laboratory

California Institute of Technology

Prepared Under Contract No. NAS 7-100

National Aeronautics \& Space Administration 


\section{CONTENTS}

I. Introduction . . . . . . . . . . . . . . . . . 1

II. Molsink Functional Description . . . . . . . . . . . 3

III. Moltrap Theory . . . . . . . . . . . . . . . . . . . . 4

IV. Moltrap Analysis . . . . . . . . . . . . . . . . . . . 6

V. Chemical Pump (Ti Sublimator) .

VI. Moltrap Refrigerator . . . . . . . . . . . . . . 8

VII. Vacuum Chamber Construction Features. . . . . . . . 8

VIII. Ancillary Systems . . . . . . . . . . . . . . . . . . .

IX. Instrumentation . . . . . . . . . . . . . . . . . . . . . . 9

References . . . . . . . . . . . . . . . . . . . 11

\section{FIGURES}

1. Space molecular sink simulation facility . . . . . . . . . . . 2

2. Comparison of the distribution from a smooth wall, radial fin, and wedged fin distribution . . . . . . . . . . . . . . . 5

3. Ratio of returning to emanating molecules. . . . . . . . . . . . . . 6

4. A quartz crystal vibrating in a thickness shear-mode. . . . . . . 10

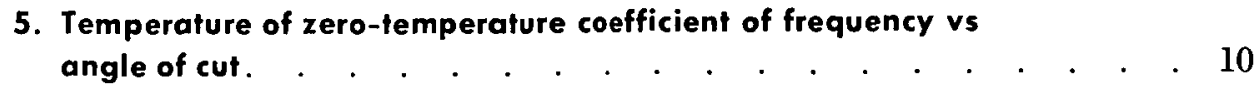

6. Quartz crystal mounted on spring-clip base . . . . . . . . . . 10 


\title{
ABSTRACT
}

\begin{abstract}
$245 \%$
This Report summarizes the results of research, design, and development efforts for a space molecular sink simulation facility now under construction. The longitudinal-wedge-fin, $21^{\circ} \mathrm{K}$ hydrogen-refrigerated, molecular-trap array has been shown to provide a capture improvement of an order of magnitude over that of smooth-walls, capturing $99.97 \%$ of the condensable molecules of $\mathrm{O}_{2}, \mathrm{~N}_{2}, \mathrm{~A}, \mathrm{CO}$, and $\mathrm{CO}_{2}$ that emanate from the test item before they can return. An electron-beam titanium sublimator will be used to pump hydrogen and, also, chemically permanently fix the cryo deposits. A $1300-\mathrm{ft}^{3} / \mathrm{min}$ mechanical pump (operated in the viscous-flow regime to eliminate backstreaming) and a 140-l/sec turbo-molecular impact pump will be used to rough pump the double-walled, double-doored 10 -ft-diam vacuum chamber and to sustain the guard vacuum. The chamber is decontaminated by glass-bead blasting in conjunction with a $250^{\circ} \mathrm{C}$ vacuum bake-out. Conventional extreme-high-vacuum and cryogenic instrumentation and controls will be used; cryogenic quartz-crystal microbalances with a sensitivity of $1 \times 10^{-10} \mathrm{~g} / \mathrm{cm}^{2}$ will be used to measure condensable molecular fluxes; and a cryogenic quadrupole mass spectrometer will be used to monitor the molecular specie emanating from the test item.
\end{abstract}

\section{INTRODUCTION}

During a spacecraft's flight, the active environments of space, such as particle and radiation fluxes, produce marked effects on many of its surfaces. The fluxes cause dislodging of the surface-absorbed gases, which are then removed by the permissive environment, the molecular sink of space. Spacecraft experience suggests that the degradation of the absorptivity-emissivity characteristic of some paints when exposed to ultra-violet radiation may be affected by the quality of the vacuum environment in which the surface coating is tested (Ref. 1); and experiments are now being conducted in a small space molecular sink simulator system, molsink, to determine the effect of the molecular sink of space on the die-off rates of spores that might be found on spacecraft components. In addition to the active environments of space, others are produced by the spacecraft itself, such as internal heat, bearing friction, and contaminant fluxes which also interact with the molecular sink of space. As an example, the cold welding of spacecraft bearings (Ref. 2) may be a function of the bearing cavity conduction to space and the amount and type of molecular flux produced by the materials within the cavity. 


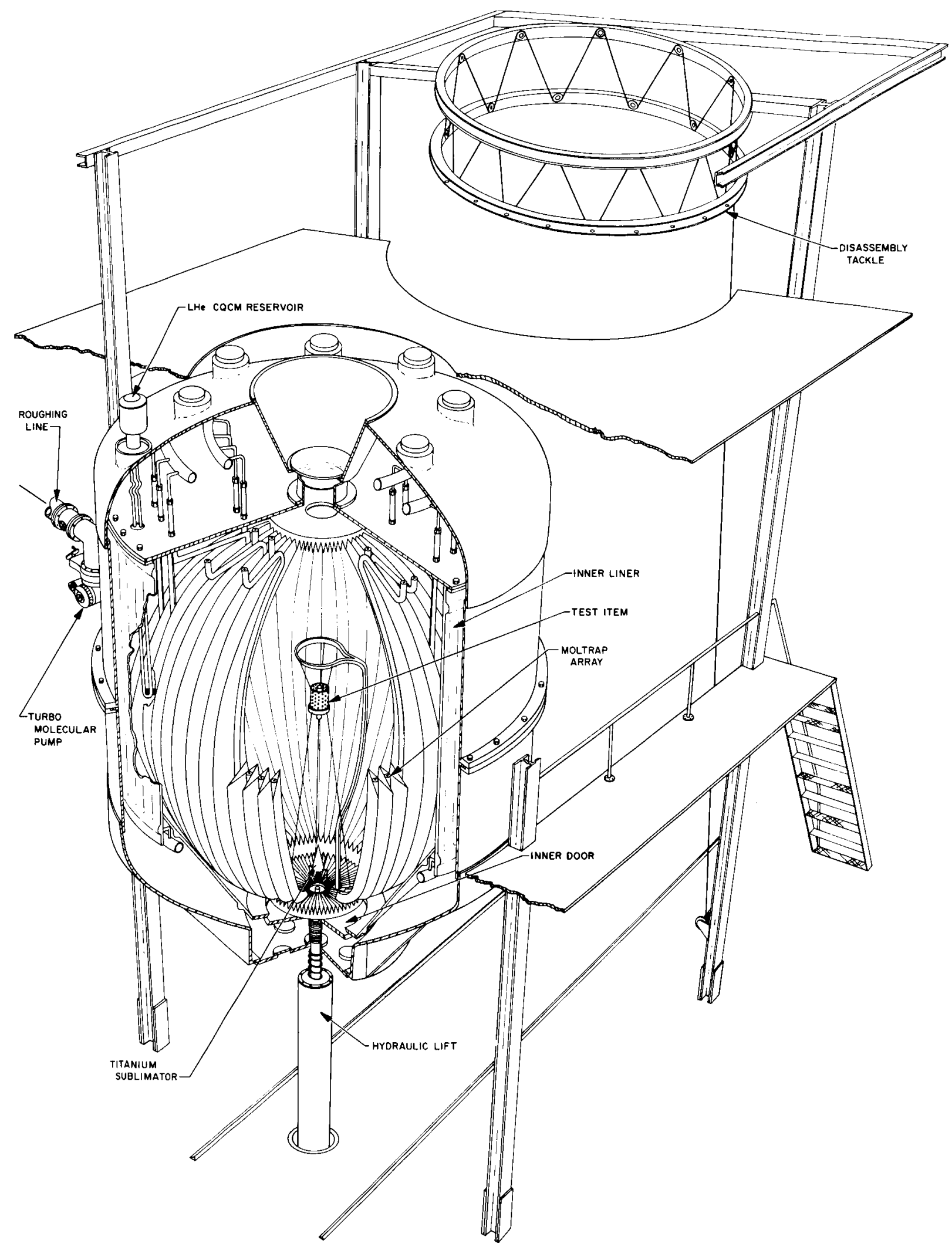

Fig. 1. Space molecular sink simulation facility 
Because of the many problems of cold welding, surface degradation, contaminant migration, and others that are encountered in sophisticated spacecraft, there is need for such a simulator as molsink in which the above mentioned problems can be investigated.

The molsink facility, illustrated in Fig. 1, is a $10-\mathrm{ft}$ diam, extreme-high-vacuum chamber with walls that cryogenically and chemically pump gases produced by the test item. The cryopumping is accomplished by a 96-in. spherical molecular trap (moltrap), of wedge-fin array, constructed of 0.016-in.-thick aluminum sheets that are spot welded to aluminum tubes; the tubes are cooled to $21^{\circ} \mathrm{K}$ by a 1000 -w refrigerator. The angles of the fins are such that their projections are tangent to a 10-in. sphere at the center of the moltrap, a configuration which has been shown to provide an order-of-magnitude capture improvement over a smooth-wall capture when the test-item gas load is from within the 10-in. spherical volume. It has been computed that approximately 35 out of every 100,000 molecules of $\mathrm{O}_{2}, \mathrm{~N}_{2}, \mathrm{~A}, \mathrm{CO}$, and $\mathrm{CO}_{2}$ emitted from a 10 -in. spherical $300^{\circ} \mathrm{K}$ test item would restrike the test item; for molecules with sticking coeffi- cients greater than $\mathbf{0 . 7 0}$, the number restriking is proportionally reduced.

The chemical pumping is accomplished by an electronbeam titanium sublimator, which is mounted on the inner door of the chamber. About $7 \times 10^{6} 1 / \mathrm{sec}$ of hydrogen can be pumped by the $2000 \mathrm{ft}^{2}$ of $21^{\circ} \mathrm{K}$ surface which is continuously being coated by the sublimator. Two fortunate by-products of this arrangement may be that the cryo-deposit is chemically fixed by the titanium, and the effective capture coefficient of the cryopumping surface is also increased.

The described facility is only partially completed at this time (February 1966). The mechanical pumps, the chamber support structure, and most of the utilities are installed. The chamber and the moltrap array are under construction, and the designs of the refrigerator and titanium sublimator are nearing completion. The instrumentation systems are under development in the research laboratory along with the experimental verification of the moltrap theory. The titanium back-streaming problem is currently under investigation.

\section{MOLSINK FUNCTIONAL DESCRIPTION}

The chamber is designed so that it can be disassembled periodically and glass-bead blasted to remove accumulated contaminants. The lower part of the outer chamber and tight inner liner can be lowered by the hydraulic lift, permitting the moltrap array to be removed by the overhead tackle. After cleaning, the chamber will be reassembled and pumped down by a $1300-\mathrm{ft}^{3} / \mathrm{min}$ mechanical pump and a turbo molecular impact pump (turbomol) to $4 \times 10^{-3}$ torr during a bakeout at $250^{\circ} \mathrm{C}$ for $100 \mathrm{hr}$. If the chamber has not been exposed to atmospheric contaminants or grossly contaminated test items, a shorter vacuum bake without disassembly can be used.

The test item is prepared and mounted on the double door in a $\mathrm{GN}_{2}$ purged skirt under the chamber. The chamber is backfilled with high-purity argon, the vacuum bake-out door removed, and the test item inserted by raising the double door on the hydraulic lift.
While the inner door is open, the chamber is rough pumped by the mechanical pump and maintained at $100 \mu$ by an argon sweeping purge to prevent oil backstreaming: during this time, the inner liner and the moltrap array are cooled to $77^{\circ} \mathrm{K}$. The inner door is closed and its gold wire gasket is loaded by the hydraulic lift. While the turbomol, in conjunction with cryopumping from the moltrap manifolds, pumps the guard vacuum to below $1 \times 10^{-i s}$ torr, the moltrap is cooled to $21^{\circ} \mathrm{K}$, and the electronbeam titanium sublimator is started.

The outgassing rate of the test item is monitored with cryogenic quartz-crystal microbalances (CQCM), which are described under Instrumentation (see also, Ref. 3); and the titanium sublimator, which is monitored and controlled by a warm quartz crystal microbalance, is made to match this gas load with an efficient titanium sublimation rate. One of the early experiments planned for the molsink is a determination of this rate. The gas species 
evolved from the test item can be qualitatively measured with a cryogenic quadrupole mass spectrometer.

A shuttered, 12-in.-diam double quartz window is provided in the top of the chamber, through which a solar simulator can impinge its beam on the test item and visual inspection can be made.

The test item is unloaded from the chamber into the $\mathrm{GN}_{2}$ purged skirt area under the chamber by relaxing the hydraulic lift and back-filling the chamber with hot, high-purity argon (an easily pumped, inert gas that does not condense at $77^{\circ} \mathrm{K}$ ) while the moltrap and inner liner are still cold to prevent evaporation of the cryo-deposit and contamination of the test item. The back-fill gas temperature is controlled so as to cancel out the cooling of the test item due to gaseous conduction. When the test item clears the door port, the vacuum bake-out door is held in place, and the chamber is rough pumped to $100 \mu$ for warm up for the start of the bake-out cycle.

\section{MOLTRAP THEORY}

If it is assumed that about $1 \times 10^{7} \mathrm{~mol} / \mathrm{cm}^{2} / \mathrm{sec}$ strike surfaces in space, it would take $3 \mathrm{yr}$ or more for a monolayer to form, provided all striking molecules stick to the surface (Ref. 4). Fortunately, the surface-effect phenomena that are of interest to the function of spacecraft do not require periods of this length to become apparent; a period of minutes, hours, or days may be sufficient, depending on the particular experiment being performed.

In the molsink chamber, the monolayer formation time (MFT) is directly related to the type and quantity of gas being evolved from the test item and to the percent of these gas molecules that are allowed to return to the test item by the moltrap. This percent of returning molecules can be minimized by the design of the moltrap and is, therefore, the major measure of performance for this type of simulator.

A molecule hitting a surface can do one of two things; either it can be captured by the surface - because of cryogenic, physical, or chemical sorption - or it can rebound. If it is caught, it may remain on the surface for a short time and then return to the void, or, alternately, it may stay on the surface more or less perrnanently.

If it is not captured but, rather, instantaneously rebounds, the direction in which it is reflected is related to the direction of incidence. If, however, the molecule remains on the surface for a finite time, there is no such relation; in this case, the direction in which the molecule returns is governed only by the conditions of the surface.

Knudsen's Law states that the number of molecules emerging from the surface in a certain direction is proportional to the cosine of the angle made by that direction and the normal to the local surface. It has been demonstrated (Ref. 3) that the gas molecule will reflect specularly only when the product of the cosine of the angle of incidence and the average height of the inequalities of the surface are less than the material wavelength of the gas molecule. Only extremely highly polished metal surfaces and cleaved surfaces of crystals are smooth enough to produce any specular reflection of molecules. Therefore, all molecules that rebound from engineering surfaces do so without regard to their direction of incidence.

There are two types of macroscopic array configurations, as depicted in Fig. 2, that could be used to increase the effectiveness of a molecular trap. The major difference is the shape of the distribution of the reflected flux. A wedge-fin array was chosen, since it minimizes the number of molecules returned to a centered test item; the radial-fin configuration minimizes the total number returned to the entire test volume, but it permits return of just as many molecules to a centered test item as does a smooth wall. 


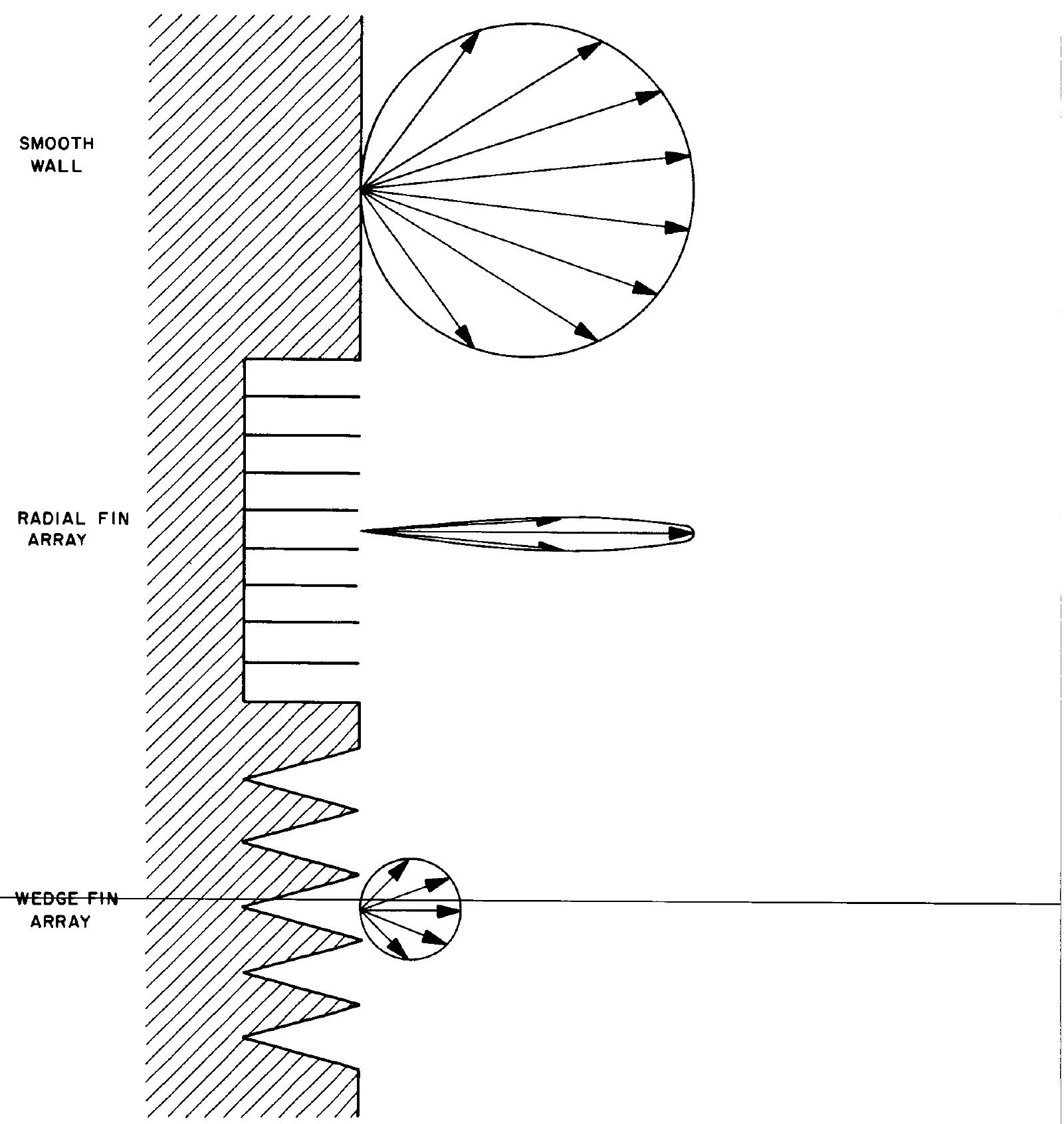

Fig. 2. Comparison of the distribution from a smooth wall, radial fin, and wedged fin distribution 


\section{MOLTRAP ANALYSIS}

The MOLTRAP array used in the MOLSINK chamber can be analyzed using the following relationship (Ref. 5):

$$
\begin{aligned}
\frac{\text { No. returned mol }}{\text { No. evolved mol }}= & \left(\frac{\text { test item diam }}{\text { moltrap diam }}\right)^{2} \\
& \times(\% \text { rebounding mol }) \\
& \times\left(\frac{\text { tangent sphere diam }}{\text { moltrap diam }}\right)
\end{aligned}
$$



Fig. 3. Ratio of refurning to emanating molecules
From examination of Fig. 3 and this equation, it is apparent that the ratio of returning to emanating molecular flux is proportional to the square of the ratio of testitem to moltrap diameters, provided they are concentric spheres. This is a straightforward area ratio and applies to all chambers. This ratio is reduced by the fraction of molecules that rebound from the surface of the fins. This is one minus the sticking coefficient and applies to all chambers. The third factor is the effect of the wedge fin moltrap, which can be expressed as the ratio of the tangent sphere diameter (the sphere to which the fin planes are tangent) to the moltrap diameter; it is unique to the molsink chamber.

This equation does not account for the fact that the edges of the fins are not perfectly sharp nor that some of the molecules that miss the test item will rebound again. It does assume that the test item and moltrap are both spherical, and that the test item is smaller than the tangent sphere. Only those elements of the test item that produce high gas loads, such as the electronics on a TV camera, need to be within the tangent sphere in order that the moltrap perform efficiently.

The moltrap has an effective diameter of 96 in.; its fins, which operate at $21^{\circ} \mathrm{K}$, are all tangent to an imaginary 10 -in. sphere. If the test item were a 10 -in. sphere that emitted gases over its entire surface with capture coefficients of about 0.70 on $21^{\circ} \mathrm{K}$ surfaces $\left[\mathrm{O}_{2}, \mathrm{~N}_{2}, A\right.$, $\mathrm{CO}, \mathrm{CO}_{2}$ at $300^{\circ} \mathrm{K}$ (see Ref. 6) ], then for every 100,000 molecules emitted, only about 35 would restrike the test item; this ratio includes increases due to the blunt fin edges, about $1 \%$ (Ref. 7), and multiple wall collisions, about $0.7 \%$ (Ref. 8). Experimental verification of the above relationships have been performed in a small molsink system using CQCMs (Ref. 9).

The monolayer formation time for nitrogen onto the test item can then be estimated: for example if the $300^{\circ} \mathrm{K}$ 10-in. spherical test item evolves nitrogen at the rate of $1 \mathrm{monolayer} / \mathrm{sec}$, or $2 \times 10^{-5}$ torr $1 / \mathrm{sec}^{-\mathrm{cm}^{2}}$, and if the contaminant sensitive surface of the test item captures $10 \%$ of all the nitrogen molecules that strike it, then it would take

$$
\frac{1}{\left(3.5 \times 10^{-4}\right) 0.10} \approx 30,000 \mathrm{sec}, \text { or } 8 \mathrm{hr}
$$

to form a monolayer. 
The solid nitrogen on the moltrap surface will provide a partial pressure within the chamber equal to its vapor pressure at $21^{\circ} \mathrm{K}$ if the moltrap surfaces become saturated with un-chemsorbed nitrogen. This partial pressure would be $1 \times 10^{-10}$ torr (Ref. 10) and would provide a monolayer formation time from this source of 180,000 sec, or about $50 \mathrm{hr}$ (Ref. 8), again assuming $10 \%$ of all the nitrogen that strikes the test item is captured.

If these two sources are combined, then

$$
\frac{1}{\mathrm{MFT}}=\frac{1}{8}+\frac{1}{50}
$$

With the stated assumptions, the monolayer formation time would be approximately $7 \mathrm{hr}$. It is felt that this example is conservative, because a gas flow of this magnitude could be maintained only by a leak from a pressurized cavity; the actual capture coefficient for the nitrogen on the moltrap will be greater because of the titanium chemsorption, and the moltrap surfaces will not become saturated with free nitrogen because of the titanium chemically fixing the cryo-deposit.

It is evident that the nature and specie of molecules evolved from each specific test item greatly influence the molsink performance in terms of MFT. One of the major attributes of this molsink design is the ability to accommodate very large gas loads ("dirty" test items) while still maintaining an MFT measured in hours or days.

\section{CHEMICAL PUMP, TITANIUM SUBLIMATOR}

An electron-beam gun mounted inside a $\mathrm{LN}_{\mathrm{z}}$-cooled conical shield impinges its beam on a $\mathrm{LN}_{2}$-cooled zonerefined rod of titanium mounted in the center of the moltrap door shroud; this action causes evaporation of titanium onto the $2000 \mathrm{ft}^{2}$ of moltrap array surfaee. Hydrogen is reported to be pumped at $3.8 \mathrm{l} / \mathrm{sec}^{\mathrm{cm}} \mathrm{cm}^{2}$ of titanium coated surface (Ref. 11). Therefore, the moltrap is expected to pump hydrogen at $7 \times 10^{\circ} \mathrm{l} / \mathrm{sec}$.

Since the titanium evaporates with a cosine distribution, the location and orientation of the source will produce a uniform coating on the moltrap. Efficient titanium utilization may then be made with the use of a quartz crystal microbalance sublimation control system, which consists of a $\mathrm{LHe}$ cooled quartz crystal $\left(4^{\circ} \mathrm{K}\right)$ that condenses the test item molecular flux in combination with a warm quartz crystal $\left(300^{\circ} \mathrm{K}\right)$ that condenses the titanium flux, only. This system allows the rate of titanium evaporation to be controlled and matched to that required by the test item gas load.
In addition to pumping hydrogen at very high speeds, this system may also pump helium by ionization in the electron beam, followed by ion burial in the moltrap surface and permanent physical covering of the site by the titanium coating. Because of the small size of the electron beam, the helium pumping rate will be very low; sources of helium must, therefore, be minimal. The freshly deposited active titanium may also chemically combine with the active cryopumped deposits and, thus, may permanently fix them to the surface, reducing the problem of evaporation from moltrap temperature increase.

Finally, the titanium may improve the effective sticking coefficient of the moltrap surface by chem-sorbing a portion of the condensable molecules that would ordinarily rebound. (The rebounding molecules partially accommodate and, thus, have a finite residence time on the surface.) The magnitude of this effect remains to be demonstrated. 


\section{MOLTRAP REFRIGERATOR}

The moltrap requires $1000 \mathrm{w}$ of refrigeration at $21^{\circ} \mathrm{K}$ for continuous periods of up to a year. The power requirements are due to the combined radiation loads of the test item, $\mathrm{LN}_{2}$ walls, and the titanium sublimator, as well as to the conduction losses of the moltrap feedthroughs. The temperature requirement is predicated on the vapor pressure and sticking coefficient of the common gases that normally evolve from test items. The extended period of reliable continuous operation is required by the lengthy times spent in transfer between the planets by the spacecraft; these periods must be duplicated for real-time testing. Since helium not only leaks and diffuses more easily through joints and metals than hydrogen, but is also more difficult to pump (estimated at 10 to $1000 \mathrm{l} / \mathrm{sec}$ ) than hydrogen (estimated at
$7 \times 10^{i} \mathrm{l} / \mathrm{sec}$ ), the moltrap refrigeration system will have the optional capability of using hydrogen. It is hoped that the leak-and-diffusion problem will not force the use of this option because of safety problems that are created by use of hydrogen.

The design of the refrigeration system is not completed at this time; however, it is felt that a dry labyrinth-sealtype compressor that would feed helium to a turbine expansion engine through a $\mathrm{LN}_{2}$ precooler and counterflow heat-exchanger would meet the above requirements. The optional configuration would be achieved with a gravity-convection-pumped liquid-hydrogen loop fully contained within the chamber.

\section{VACUUM CHAMBER CONSTRUCTION FEATURES}

The 10-ft-diam carbon-steel outer chamber is supported by two columns so that its double bottom-opening 24-in. door port is $9 \mathrm{ft}$ above the main floor. The inner liner, constructed of standard $304 \mathrm{~L}$ stainless steel corrugated crycpanel, is supported on eight pins projecting vertically from the door port flange and is stabilized by teflon blocks around its periphery. This vacuum-tight $\mathrm{LN}_{\text {. }}$ cooled liner provides a barrier between the test volume and the warm chamber walls, elastomeric seals, and other contaminant sources. It is designed so that all of the welds or joints that are exposed to the test volume vacuum are guarded by the vacuum between the inner and outer chamber. That is, no weld, joint, or connection has a fluid on one side and the test volume vacuum on the other; all such joints or connections in the fluid or gas lines are made within the guard vacuum space between the inner and outer vessels. Thus, the effect of the inevitable, undetectable leak on the test volume vacuum is greatly reduced.

The aforementioned guarded joint feature is carried through with the moltrap array, whose elements (50 pairs of wedge fins) are suspended from the $\mathrm{LN}_{\mathrm{z}}$-cooled inner liner bulkhead plate by their aluminum hairpin cooling tubes. Thin (0.016-in.) sheets of aluminum are spot welded to these tubes to form the 96-in. spherical longitudinal-wedge-fin moltrap array. These fins are arranged so that they have a 13- to 14-deg included angle between them and are tangent to a 10 -in. sphere at the center of the chamber. Since the longitudinal fins diminish in height and spacing as they approach the poles of the array, there is insufficient room between the fins for the cooling tubes in these two zones. The door and window array elements are, therefore, machined from solid aluminum. 


\section{ANCILLARY SYSTEMS}

Bake-out heat is provided by passing heated $\mathrm{GN}_{2}$ through the inner liner; in addition, a radiant electrical heater element, which is mounted on a dummy door, sustains the bake-out temperature and, thus, conserves $\mathrm{GN}_{2}$.

The double door closes the outer chamber, acts as a high-vacuum valve between the test volume vacuum and the guard vacuum, and provides support points and feed-throughs for the test item. The test-item support consists of a catheter-fed, $\mathrm{LN}_{2}$-cooled, sharp knife-edge strut which provides overhead suspension points by which the test item may be hung by its own instrumentation wires. These wires are led up the back side of the strut and, thus, their contribution to the back reflection is minimized.

The outer door is sealed with a Viton Gask-O-Seal, and the inner door is sealed by a 0.010 -in. gold wire that is crushed by the 20,000 -lb hydraulic door-lift actuator. This uniformly loaded seal will survive the temperature extremes $\left(77^{\circ} \mathrm{K}\right.$ to $\left.250^{\circ} \mathrm{C}\right)$ and provide an adequate seal between the guard vacuum and the test volume vacuum.
The hydraulic actuator raises and lowers the double door and opens and closes the inner door; it is used, also, to lower the bottom section of the outer chamber, when the inner liner and moltrap array are removed for cleaning and repair.

The window is composed of an outer, optically flat, 1-in.-thick quartz plate, which withstands the atmospheric pressure, and an inner, optically flat, thin quartz plate, which separates the test volume vacuum from the guard vacuum. The inner window is shielded from the test item by a $\mathrm{LN}_{2}$-cooled shutter that is supported on a rotary-motion feed-through. The shutter is provided with a molecular trap surface consisting of machined, circumferential, sharp V-grooves. The outer window is sealed with a Viton Gask-O-Seal and is held in place by gravity, thus acting as an over-pressure relief for the outer chamber.

A frangible-disc burst diaphragm provides protection for the inner liner and has disc cutters that ensure rupture at 1 psi differential pressure in either direction.

\section{INSTRUMENTATION}

Conventional instrumentation is used to monitor the pressure; a high-pressure nude ionization gauge monitors the guard vacuum, and a standard nude ionization gauge monitors the test-volume vacuum. Thermocouple gauges are used to monitor the pressures in the roughing system and the vacuum insulation of the refrigerator.

A cryogenic quadrupole mass spectrometer, which is mounted on one of the moltrap cooling tubes, monitors the molecular species emanating from the test item.
As mentioned before, a $4^{\circ} \mathrm{K}$ cryogenic quartz crystal microbalance and a $300^{\circ} \mathrm{K}$ (room temperature) quartz crystal microbalance are used to monitor and control the operation of the titanium sublimator. A $21^{\circ} \mathrm{K}$ CQCM, mounted on the moltrap, and a $77^{\circ} \mathrm{K}$ CQCM, mounted on the inside of the inner liner, are also exposed to the molecular flux from the test item and are used in conjunction with the $4^{\circ} \mathrm{K}$ CQCM to quantitatively calibrate the cryogenic quadrupole mass spectrometer, as well as to provide quantitative data on the three classes $(4,21$, 
and $77^{\circ} \mathrm{K}$ ) of condensables emanating from the test item. Other CQCM instruments are used to monitor any possible backstreaming from the mechanical roughing pumps and the turbomol pump.

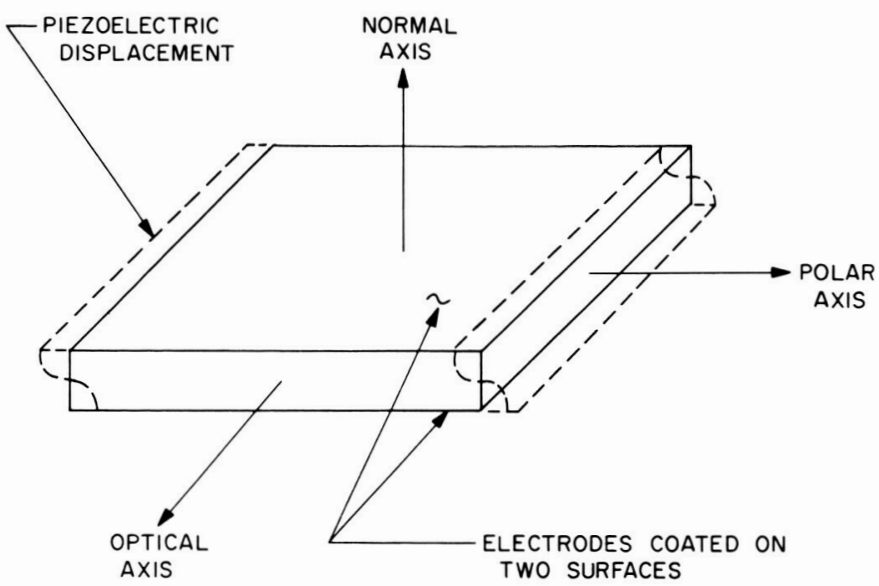

Fig. 4. A quartz crystal vibrating in a thickness shear-mode

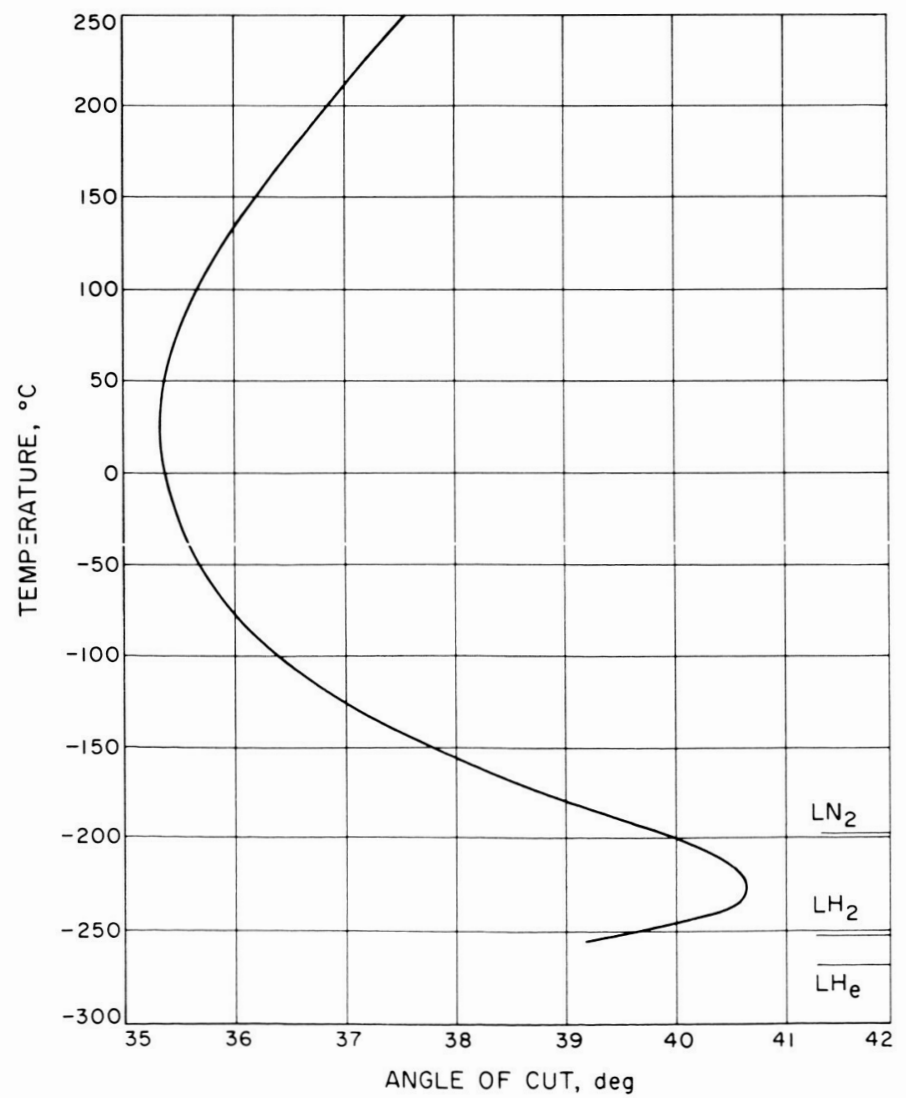

Fig. 5. Temperature of zero-temperature coefficient of frequency vs angle of cut
Properly cut quartz crystals are very sensitive, repeatable, fast, but non-linear thermometers. They are used in conjunction with thermocouples to monitor the temperature of the various chamber and refrigerator cryogenic components.

The level control of the various $\mathrm{LN}_{2}, \mathrm{LH}_{2}$, and $\mathrm{LHe}$ reservoirs is accomplished with low-frequency quartz crystals whose oscillations are damped by the cryogenic liquid but not by the gas. In the case of LHe, this method of level detection is advantageous because no significant heat is generated within the reservoir.

A quartz crystal vibrating in a thickness shear-mode (as illustrated in Fig. 4) is, over a wide range, frequency sensitive in a linear fashion to changes in mass and can, thus, measure the rate at which a molecular flux condenses on its surface at a particular temperature.

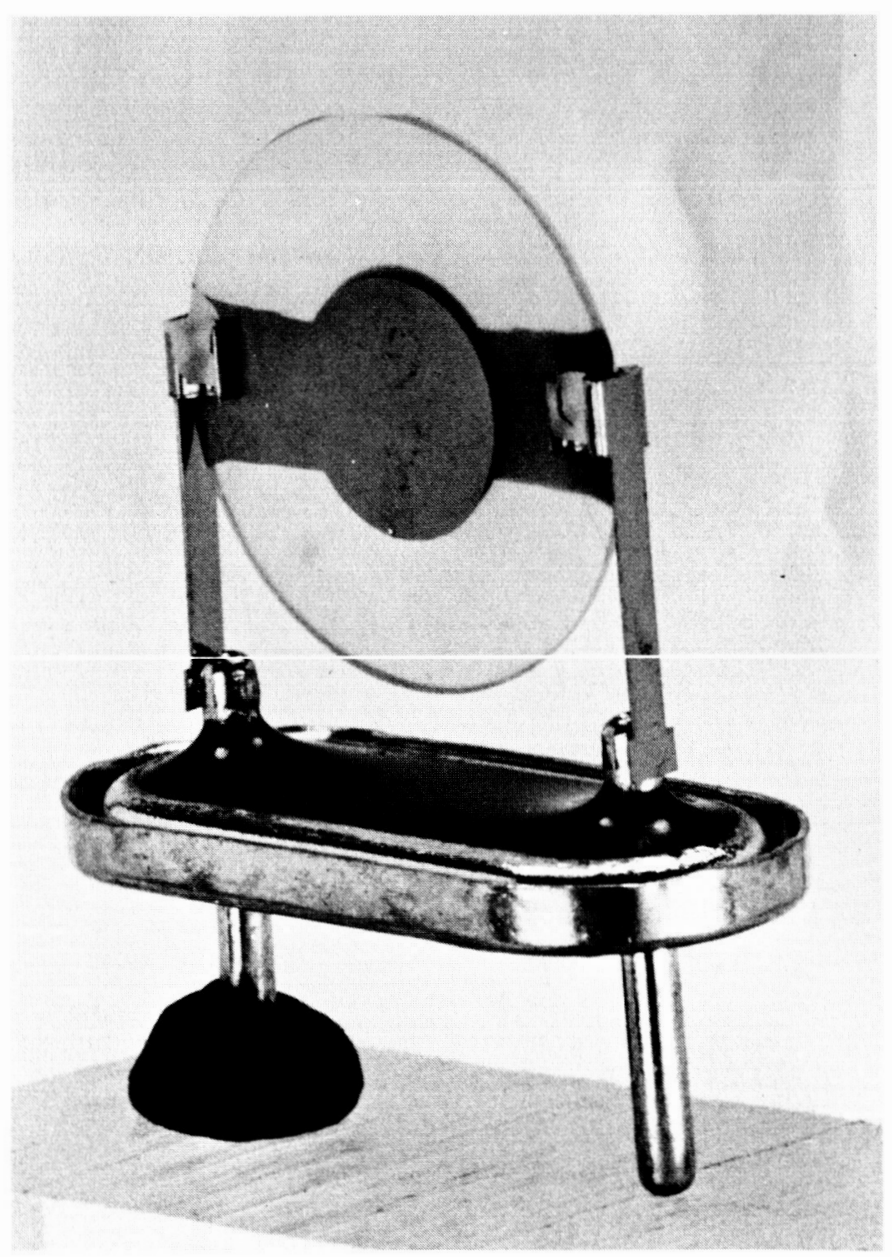

Fig. 6. Quartz crystal mounted on spring-clip base 
Sensitivities as high as $1 \times 10^{-10} \mathrm{~g} / \mathrm{cm}^{2}$ (a gas monolayer is approximately $10^{-8} \mathrm{~g} / \mathrm{cm}^{2}$ ) can be achieved by operating the crystal at the temperature at which changes in temperature produce small changes in frequency (Ref. 12). This turnover point of a crystal can be adjusted by the angle at which the crystal is cut $\left(39^{\circ} 49^{\prime}\right.$ for a crystal mounted on the $\mathrm{LN}_{2}$ cooled holder). Figure 5 roughly plots the temperature of turnover vs the angle of cut (Ref. 13).

A quartz crystal, as shown in Fig. 6, is either attached to a wall or a shroud, or it is mounted on its own reser- voir-fed U-tube cryogenic holder and its low capacitance (100 pf) mechanically restrained leads are fed through the inner and outer walls of the chamber to an oscillator, which is mounted on the outer flange.

An oscilloscope with a 4-channel plug-in module is used to diagnostically examine the waveshape of the oscillator output and to sequentially switch between each of four different CQCMs. An electronic counter, digitalto-analog converter, digital printer, and strip-chart recorder are used to record the vertical output of the scope, thus sequentially recording four CQCM frequencies.

\section{REFERENCES}

1. Lewis, D. W., Mariner IV Absorptivity Standard, TR 32-734, Jet Propulsion Laboratory, CIT, Pasadena, Calif., March 1, 1966.

2. Adams, L., Stephens, J., "Testing the Mariner-C TV Shutter Solenoid in a Space Molecular Sink Simulator," Space Programs Summary No. 37-36, Vol. II, Jet Propulsion Laboratory, CIT, Pasadena, Calif., November 1965.

3. Stephens, J. B., "Space Molecular Sink Research Laboratory-Cryogenic Quartz Crystal Microbalance," Space Programs Summary No. 37-34, Vol. IV, Jet Propulsion Laboratory, CIT, Pasadena, Calif., August 1965.

4. deBoer, J. H., The Dynamical Characteristics of Adsorption, Oxford University Press, London, 1959, p. 20

5. Wallace, D. A., Chuan, R. L., Rogers, K. W., "Analysis of High Sticking Coefficient Cryopanel Arrays for the Simulation of the Permissive Nature of Space Environment," Celestial Research Corp., South Pasadena, Calif., 1965.

6. Dawson, J. P., "Prediction of Cryopumping Speeds in Space Simulation Chambers," CP-11, AlAA Space Simulation Testing Conference, Pasadena, Calif., November 1964 .

7. Stephens, J. B., Wallace, D. A., "Design for a Space Molecular Sink Simulator," TR 32-688, Jet Propulsion Laboratory, CIT, Pasadena, Calif., November 15, 1964.

8. Barrington, A. E., High Vacuum Engineering, Prentice-Hall Inc., Englewood Cliffs, N. J., 1963, p. 188.

9. Stephens, J. B., "Space Molecular Sink Research Laboratory," Space Programs Summary No. 37-30, Vol. IV, Jet Propulsion Laboratory, CIT, Pasadena, Calif., December 1964. 


\section{REFERENCES (Cont'd)}

10. Roberts, R. W., Vanderslice, T. H., Ultra High Vacuum and Its Applications, Prentice-Hall, Inc., Englewood Cliffs, N. J., 1964, p. 92.

11. Clausing, R. R., "A Large-Scale Getter Pumping Experiment Using Vapor-Deposited Titanium Films," Amer. Vacuum Soc., Trans. of the Eighth National Vacuum Symposium, 1961, pp. 345-356.

12. Waters, P. M., and Raygor, P. O., A Quartz Crystal Microbalance, Research Report 62-115-454-RZ, Westinghouse Research Laboratory, Pittsburgh, Pa., 1962.

13. Phelps, F. P., Goodwin, R. D., and Morgan, A. H., Investigation of Stability of Quartz Resonators at Low Temperatures, Second Quarterly Progress Report for July 1956 to September 1956, Report NBS 5021, National Bureau of Standards, U. S. Department of Commerce, Boulder, Colo., November 1956.

\section{ACKNOWLEDGMENT}

The author wishes to express his indebtedness to Dr. R. Chuan and D. A. Wallace of Celestial Research Corporation, South Pasadena, California, for their help with the conceptual design and analysis of the molsink facility. 